\title{
COLONIALIDADE: \\ DIMENSÕES-CHAVE E IMPLICAÇÕES CRÍTICAS ${ }^{1}$
}

\author{
Coloniality \\ Key Dimensions and Critical Implications
}

\author{
Noah DE LISSOVOY \\ Universidade do Texas em Austin \\ delissovoy@austin.utexas.edu \\ Raúl Olmo FREGOSO BAILÓN \\ Universidade de West Chester \\ rfregosobailon@wcupa.edu \\ https://orcid.org/0000-0001-6405-9990 \\ Tradução de Flavia GULAK MAIA \\ Universidade Federal do Paraná \\ flaviagulakm@gmail.com \\ https://orcid.org/0000-0002-0123-9043
}

RESUMO: Emergindo da investigação sociológica e filosófica a respeito da história do encontro colonial na América Latina, a noção de colonialidade (assim como a teoria decolonial, campo mais amplo com a qual está agora associada) tornou-se um recurso teórico crucial para estudiosos de várias áreas. Investigações da estrutura e dos processos da colonialidade desafiam ideias amplamente aceitas sobre poder, conhecimento e identidade na modernidade, o que traz implicações significativas para a filosofia educacional. No entanto, os estudos sobre decolonialidade são menos conhecidos entre teóricos da educação do que a teoria pós-colonial, com a qual compartilha muitos interesses, mas também diferenças fundamentais. Em nossa apresentação das noções de colonialidade, descrevemos primeiro a história e as principais dimensões desta ideia. A segunda parte do artigo desenvolve várias das principais implicações da noção de colonialidade para estudiosos e educadores, com particular atenção para como essa tradição oferece uma forma de repensar categorias familiares para a Teoria Crítica e a Pedagogia. PALAVRAS-CHAVE: Colonialidade; Colonialidade do poder; Pedagogia; Teoria crítica.

\footnotetext{
${ }^{1}$ Publicação original: LISSOVOY, Noah De; BAILÓN, Raúl Olmo Fregoso. Coloniality: key dimensions and critical implications. In: FORD, Derek R. (ed.). Keywords in radical philosophy and education: common concepts for contemporary movements. Leiden; Boston: Brill Sense, 2019. cap. 7, p. 83-97.
} 


\begin{abstract}
Emerging from sociological and philosophical inquiry into the history of the colonial encounter in Latin America, the notion of coloniality (and the larger field of decolonial theory with which it is now associated) has become a crucial theoretical resource for scholars across a range of disciplines. Investigations of the structure and processes of coloniality challenge received ideas about power, knowledge, and identity in modernity, and these investigations have significant implications for educational philosophy. Nevertheless, decolonial scholarship remains less known among educational theorists than postcolonial theory, with which it shares many concerns but from which it also sharply differs in crucial respects. In our presentation of the notion of coloniality, we first describe the history and key dimensions of this idea. The second part of the article develops several of the most crucial implications of the notion of coloniality for scholars and educators, with particular attention to how this tradition offers a rethinking of familiar categories in critical theory and pedagogy. KEYWORDS: Coloniality; Coloniality of power; Pedagogy; Critical theory.
\end{abstract}

\title{
UMA INTRODUÇÃO À COLONIALIDADE
}

A perspectiva eurocêntrica do conhecimento opera como um espelho que distorce o que reflete, como podemos ver na experiência histórica latino-americana (QUIJANO, 2008, p. 204).

\section{Definição}

Se olharmos com cuidado para o trabalho de Aníbal Quijano Obregón, que cunhou o termo colonialidade, veremos que esse está fundamentado na noção de colonialidade do poder. Para Quijano, a colonialidade é um modelo de poder que emerge de uma parte invisível da história. É preciso destacar como a colonialidade do poder realça a distinção entre colonialismo (uma formação social concreta) e colonialidade (uma condição política, cultural, epistemológica e simbólica mais abrangente). Contudo, além dessa distinção, é importante abordar a totalidade do conceito: colonialidade do poder refere-se ao poder que é ontologicamente colonial em sua origem e cuja articulação como ordem mundial surgiu após a invasão europeia da atual América Latina e Caribe.

A origem do termo colonialidade remete ao trabalho de González Casanova (1965) sobre colonialismo interno, no qual explica como as estruturas coloniais prevaleceram em sociedades outrora colonizadas mesmo após o surgimento de um Estado independente. 
A colonialidade existe até hoje (mesmo após o fim do colonialismo propriamente dito) devido à sua relação e organização do poder. Quando se trata de definir o conceito de colonialidade do poder, Quijano (2000) se refere a um artigo publicado em 1992 no qual enfatiza a própria dimensão do poder: “...la cultura europea se convirtió, además, en una seducción: daba acceso al poder. Después de todo, más allá de la represió, el instrumento principal de todo poder es su seducción"” (QUIJANO, 1992, p. 12-13). Além disso, a colonialidade "Era un modo de participar en el poder colonial pero también... para alcanzar los mismos beneficios materiales y el mismo poder que los europeos"3 (QUIJANO, 1992, p. 13). Como explica Castro-Gomes (2008), "Assim, a primeira característica da colonialidade do poder, a mais abrangente de todas, é a dominação por meios não exclusivamente coercitivos" (p. 281).

A dimensão mais conhecida da colonialidade é a sua distinção do colonialismo. Conforme coloca Mignolo (2008, p. 228-229), "É indicativo do mérito de Quijano ter demonstrado que a colonialidade é a dimensão geral da modernidade, distinguindo-a, dessa forma, do colonialismo. É também mérito dele trazer à luz o fato de que o surgimento do circuito Atlântico durante o século XVI fez da colonialidade constitutiva da modernidade". Essa distinção é central no debate acadêmico acerca da colonialidade e também aponta para efeitos históricos cruciais. De fato, como resultado do processo de colonialidade, não há hoje na América Latina um país no qual seja possível encontrar uma sociedade completamente autônoma (PRECIADO, 2008).

\section{Colonialidade e América Latina}

A América Latina deu origem ao capitalismo, à Europa e à modernidade como os conhecemos hoje e, portanto, também nela nasceu a colonialidade do poder. Como explica Quijano (1992) em uma de suas primeiras publicações:

Con la conquista de las sociedades y las culturas que habitaban lo que hoy es nombrado como America Latina, comenzó la formación de un orden mundial que culmina, 500 años después, en un poder global que articula todo el planeta ${ }^{4}$ (QUIJANO, 1992, p. 11).

\footnotetext{
2 “.... cultura europeia tornou-se, além disso, uma sedução; ela dava acesso ao poder. Afinal, além da repressão, o principal instrumento de todo poder é a sedução".

3 "Era um modo de participar do poder colonial, mas também (...) alcançar os mesmos benefícios materiais e o mesmo poder que os europeus".

4 "Com a conquista das sociedades e culturas que habitavam o que hoje é chamado América Latina, iniciou-se a formação de uma nova ordem mundial. Essa ordem culminou, 500 anos depois, em um poder que abrange todo o planeta".
} 
Em outras palavras, o primeiro sistema-mundo verdadeiro foi mundialmente imposto pela Europa após a invasão ibérica do que hoje é conhecido como América Latina; esse processo começou primeiro no Caribe e continuou no resto do continente. Apesar dos impérios asteca, inca, chinês, egípcio e greco-romano existirem antes de 1492, um sistemamundo propriamente dito começou após a invasão espanhola da América compreender três elementos que, posteriormente, afetariam a vida cotidiana das pessoas pelo mundo: capitalismo, colonialidade do poder e eurocentrismo (QUIJANO, 2000). A América ${ }^{5}$ foi a primeira construção geopolítica global; "a Europa foi a segunda e foi constituída como uma consequência da América, não o inverso" (QUIJANO, 2008, p. 200).

A África foi incorporada ao capitalismo e à modernidade com o comércio atlântico de escravizados, que começou no século XVI como uma forma de fornecer a força de trabalho livre e não remunerada necessária para construir o capitalismo e a sociedade moderna. No entanto, “... os europeus se convenceram, a partir de meados do século XVII, mas sobretudo durante o século XVIII, que de alguma maneira eles se autoproduziram como civilização" (QUIJANO, 2008, p. 200). É importante lembrar que o que hoje é a América Latina foi o centro da principal rota do comércio mundial entre a Ásia e a Europa, unindo os oceanos Atlântico e Pacífico. O território colonial do Império Espanhol, conhecido como "A Nova Espanha", abrangeu não apenas a maior parte dos Estados Unidos atual, mas também as Filipinas. A cidade de Manila tornou-se a capital das Índias Orientais espanholas em 1571 e a rota do "Galeão Manila” estendeuse, de 1565 a 1815, das Filipinas a San José del Cabo, Acapulco, Veracruz e então para a Espanha e o resto da Europa. Por 250 anos, a América Latina foi a articulação do mercado internacional que conectou a Ásia, os oceanos Pacífico e Atlântico e a Europa. San José del Cabo (México), e não Nova Iorque, era a cidade de destaque no mapa. É claro que a América do Norte seria colonizada pelos britânicos um século depois. O século XVIII foi caracterizado pelo deslocamento de poder do sul do circuito comercial do Atlântico para o norte (MIGNOLO, 2008). No século XIX, as nações latino-americanas foram cooptadas pela doutrina do "destino manifesto" dos Estados Unidos; como resultado, muitas sociedades latino-americanas ainda hoje podem ser caracterizadas como coloniais.

Só é possível entender a noção de colonialidade baseando-se em uma consideração da teoria da dependência, uma contribuição intelectual original da América Latina. A teoria da dependência explicou como a América Latina formou-se histórica e estruturalmente dependente dentro de uma lógica global de centro-periferia. Como explica Quijano: "A subordinação veio bem mais tarde, como consequência da dependência e não o inverso"

\footnotetext{
${ }^{5}$ Usamos o termo América para indicar todo o continente, do Alasca à Argentina. Revista X, v. 16, n. 1, p. 101-117, 2021.
} 
(2008, p. 215). Todas as manhãs, países enriquecidos precisam de café, banana e até drogas para suas populações; como resultado, a América Latina os enriqueceu à sua própria custa:

\begin{abstract}
Durante a crise econômica de 1930, a burguesia, que detinha a maior parte do capital comercial da América Latina (especificamente na Argentina, no Brasil, México, Chile, Uruguai e, em certa medida, na Colômbia), foi forçada a produzir localmente produtos muito consumidos que antes eram importados. Esse período foi o começo de um sistema peculiar do qual decorreu a industrialização dependente da América Latina: bens importados para consumo ostensivo (...) substituíram produtos locais destinados a esse mesmo consumo (QUIJANO, 2008, p. 215).
\end{abstract}

A teoria da dependência explica como o subdesenvolvimento na América Latina foi economicamente projetado para enriquecer as nações abastadas da América do Norte e da Europa. Dessa forma, ela é a base do conceito de colonialidade.

\title{
Aspectos-chave da colonialidade
}

A colonialidade compreende várias dimensões que, juntas, articulam o modelo de poder colonial descrito por Quijano. São elas: raça e racismo; controle de uma nova estrutura de trabalho no empreendimento capitalista europeu; a família burguesa e seu controle de sexo e gênero; controle da autoridade feito pelos Estados-nação à custa das colônias; eurocentrismo enquanto controle da subjetividade (QUIJANO, 2008). O último eixo de controle é a base para a dimensão epistemológica da colonialidade do poder (FREGOSO BAILÓN, 2015a).

Antes da invasão do que é hoje a América Latina, ser europeu significava apenas estar ligado a uma localização geográfica específica, mas, após a invasão, isso passou a ter uma conotação racial que, por sua vez, dava acesso ao poder: "Apesar da ideia de raça já estar em evolução durante o período da guerra da reconquista na Península Ibérica, foi somente com a formação de um sistema-mundo no século XVI que ela se tornou a base epistêmica do poder colonial" (CASTRO-GOMEZ, 2008). Começando com as primeiras viagens de escravizados nos anos 1500, os africanos sofreram com a distinção racial previamente construída em relação aos povos indígenas em 1492. A raça enquanto categoria veio primeiro, antes da ideia de cor; só então, pouco a pouco, a cor passou a significar a própria raça (QUIJANO, 2000).

Dessa forma, uma nova estrutura de trabalho foi articulada em dois continentes: na América e na África, os europeus se deram ao privilégio de se nomearem brancos, assim com a opção de mercantilizar as outras cores de pele, transformando-as na força 
de trabalho não remunerada e colonizada do mercado mundial (QUIJANO, 2008). A insistência contemporânea em ter uma força de trabalho descartável mostra claramente como a colonialidade é uma estrutura de poder. A noção de colonialidade do poder ajuda a entender o processo de empobrecimento das nações latino-americanas até mesmo no presente, com seus grupos de escravizados contemporâneos disponíveis para chegar à metrópole, sem que ela sequer pague pelas viagens desses grupos.

Dentro do processo de colonialidade, os povos do que hoje entende-se por América Latina foram idealizados como equivalentes ao passado, enquanto a Europa se designou como o futuro (QUIJANO, 2008). Essa linearidade simples também significava outra coisa: se esses povos colonizados eram o passado, então também eram inferiores. Suas línguas e símbolos foram tomados para representar atraso e o que é próximo à natureza.

\section{Da colonialidade à transcolonialidade}

A instrumentalização da razão pelo poder e, mais especificamente, pelo poder colonial, é um nítido indicador da modernidade. O poder colonial distorceu os paradigmas do conhecimento e abortou as promessas libertadoras da modernidade (QUIJANO, 1992). É por isso que a colonialidade é "o lado mais sombrio da modernidade ocidental", uma matriz de poder criada quando os europeus colonizaram a América Latina (MIGNOLO, 2011). Como esse conceito deriva da noção de colonialidade do poder, Mignolo (2000) amplia essa discussão para a sua ideia de matriz colonial do poder, que envolve aspectos como política (controle da autoridade), economia, controle de gênero e sexualidade e controle do conhecimento e da subjetividade. Outros autores desenvolveram mais profundamente a referida noção. Por exemplo, Nelson Maldonado-Torres (2007) propôs a ideia da colonialidade do ser, Eduardo Lander (2000) sugeriu a noção de colonialidade do conhecimento e María Lugones (2007) elaborou a ideia de colonialidade de gênero.

A modernidade é um mito arbitrário, considerando que antes da colonização da América, outros povos ao redor do mundo já haviam conquistado avanços magníficos em tecnologia (ROSAS; CALDERÓN, 2015), escrita (LARA, 2017; ROMO, 2016) e filosofia, sem mencionar sistemas militares e de guerra (QUIJANO, 2000). Se a modernidade já existia antes da sua invenção europeia, então o que os europeus criaram? A noção de colonialidade ajuda a elucidar como o que os europeus inventaram é apenas um modelo de poder, que é colonial desde o seu nascimento. As culturas chinesa, asteca e inca não são parte dessa modernidade. Como explica Dussel, "Uma vez que não são modernas, essas culturas também não podem ser pós-modernas. Elas são, simultaneamente, pré- 
modernas (mais antigas do que a modernidade), contemporâneas à modernidade e logo serão trans-modernas também" (DUSSEL, 2012, p. 42). Portanto, a resposta e a solução para os povos colonizados é a transmodernidade:

\footnotetext{
"Transversal" conota este movimento da periferia para a periferia. Do movimento feminista às lutas antirracista e anticolonial, essas "Diferenças" entram em diálogo a partir da perspectiva de suas diferentes negatividades, sem a necessidade de atravessar o "centro" da hegemonia. Frequentemente, grandes metrópoles possuem serviços de metrô que se estendem dos bairros suburbanos ao centro; entretanto, eles não oferecem conexão entre os subcentros suburbanos (DUSSEL, 2012, p. 54).
}

A transmodernidade seria uma modernidade construída precisamente a partir desse movimento lateral entre locais "periféricos". Além disso, um ponto importante do projeto de transmodernidade é a noção de uma transcolonialidade do poder na epistemologia (FREGOSO BAILÓN, 2015b), que pode nos ajudar a imaginar tanto como decolonizar o local de enunciação a partir do qual a educação e o poder são elaborados na América Latina (FREGOSO BAILÓN, 2015a), quanto o processo de senti-pensar (WALSH, 2017) que pode nos permitir transformar cartografias geopolíticas e cognitivas do conhecimento (MENDIETA, 1998).

A transmodernidade é a chave para decolonizar as ciências sociais e a filosofia: "Decolonizar as ciências sociais e a filosofia significa produzir, transformar e disseminar conhecimento que não é dependente da epistemologia da modernidade do Atlântico Norte - as normas das disciplinas e os problemas do Atlântico Norte - mas que, ao contrário, responde à necessidade das diferenças coloniais" (MIGNOLO, 2008, p. 247). Essa decolonização ajudará a transformar a lógica racializada da lesão ou violação que é notável nesta era neoliberal (DE LISSOVOY, 2012; 2015), ou seja, a trans-formar o espelho eurocêntrico que distorce o que reflete.

\section{IMPLICAÇÕES PARA A TEORIA CRÍTICA E A PEDAGOGIA}

A colonialidade, e os debates acadêmicos que a discutem, promove relevantes implicações para a teoria crítica, a filosofia em geral e, particularmente, para a teoria educacional. As teorias da colonialidade questionam muitos dos lugares comuns da tradição intelectual crítica ocidental. Para filósofos educacionais e pedagogos críticos, uma consideração do contexto determinante da colonialidade - e em particular seu enfoque 
no trabalho que o poder realiza nos níveis da ontologia e epistemologia - reformula os princípios teóricos centrais, com consequências práticas importantes para o ensino.

\section{Reconsiderando a opressão}

A noção de colonialidade desafia a tendência da teoria contemporânea de pensar separadamente as formas de opressão e de marginalização. Mesmo a teoria da interseccionalidade (por exemplo, COLLINS, 2009; EVANS-WINTERS; ESPOSITO, 2010) reproduz paradoxalmente essa concepção ao ponto de sua ênfase na singularidade das interseções particulares das opressões depender de uma noção de suas atuações autônomas. Para teóricos da interseccionalidade, forças complexamente divergentes de racismo e sexismo, por exemplo, produzem diferentes posicionamentos e pontos de vista dos sujeitos. Isso é diferente, no entanto, de uma análise que compreende diversas formas de opressão relacionadas a um projeto colonial subjacente e unificado - o que Wynter (2006) chama de "sociogenia" do Homem Ocidental e o que Dussel (1985) descreve como o proyecto ocidental fenomenológico básico. Além disso, a noção de colonialidade insiste em um itinerário geo-histórico específico - que começa com a colonização da América Latina, do Caribe e da África - como a trajetória decisiva da modernidade e seus antagonismos essenciais. Podemos pensar nisso como um dramático redirecionamento da teoria e filosofia crítica. Do ponto de vista das teorias da colonialidade, as formas de opressão social, a exploração econômica e a dominação cultural estão fundamentalmente conectadas pela problemática colonial. Por exemplo, o trabalho de Frantz Fanon $(1963$; 1967) demonstra que, no contexto colonial, a divisão absoluta entre colonizador e colonizado constitui ordens de valor, estrutura social e até da vida psíquica. Assim, mesmo quando recusam as grandes e familiares narrativas da filosofia ocidental, teorias da colonialidade e da decolonialidade também rompem com a crença pós-moderna na existência de modelos teóricos do todo.

Além disso, no que diz respeito à questão da violência e opressão, as teorias da colonialidade oferecem um questionamento agudo do marxismo, mesmo que sugiram a possibilidade de marxismos alternativos e decoloniais. Mais importante, essas teorias invertem a prioridade analítica (se não necessariamente histórica) dos momentos na teoria marxista. Essa última tradição dá sentido ao saque da América Latina e da África, assim como às ontologias de raça e cultura produzidas fora dessa história, com referência ao modo de produção capitalista emergente - que exigiu e efetuou esse saque (MARX, 1867/1976). Por outro lado, Quijano e Dussel apontam para a conquista europeia como a inauguração simultânea das ordens da colonialidade, da modernidade e do capitalismo. 
A partir dessa última perspectiva, o capitalismo remete à colonialidade, não o contrário. A segmentação do trabalho nas origens coloniais do capitalismo, no qual o trabalho assalariado (reservado aos brancos) foi coordenado de forma complexa à escravidão e à servidão por contrato (das populações negras e indígenas) dentro de um sistema capitalista mais amplo, aponta para a simultaneidade das diversas relações de exploração dentro desse sistema (QUIJANO, 2008).

Essas considerações dão suporte para a compreensão da centralidade da violência no capitalismo - em particular, a violência organizada baseada nas ontologias raciais que a colonialidade inventa. A determinação fundamental do capitalismo como um sistema racial é clara não apenas no contexto das relações globais de exploração, mas também nos sistemas racializados contemporâneos de punição (DAVIS, 2005). O constructo da colonialidade, que funciona tanto nas economias materiais quanto nos domínios imateriais do ser e do conhecimento (MALDONADO-TORRES, 2007), sustenta noções mais complexas de mais-valia e acumulação (ideias que certamente estão no coração da teoria marxista). Devemos entender essas categorias como processos ontológicos, psíquicos e espirituais, tanto quanto as entendemos como materiais (DE LISSOVOY, 2016). Assim, o racismo produz uma mais-valia para os brancos (o que é algo muito mais profundo do que sugere a noção instrumental de "privilégio") - uma mais-valia de existência, uma mais-valia de possibilidades de ser e de identidades, que se realiza em oposição a abjeção dos povos negros, pardos e indígenas em todo o mundo.

Para as teorias críticas e filosofias da educação, essas observações sugerem que devemos rearticular o foco comum da crítica ideológica (por exemplo, APPLE, 2004) com base em uma consideração dos processos de colonialismo e colonialidade. Nosso argumento também sugere que a pedagogia e a teoria pedagógica precisam envolverse com questões básicas de identidade e identificação - isto é, da política do próprio ser. O pensador político indígena dos séculos XVI e XVII, Guamán Poma de Ayala (2006), foi forçado pelo mundo colonial em que viveu a defender os indígenas não apenas como sujeitos merecedores de dignidade e respeito, mas também como agentes históricos e membros da família humana; contra a violência da colonialidade, esse argumento ainda precisa ser formulado até nossos dias. Desafiar sistemas de opressão, como pretende a Pedagogia Crítica tradicional, significa confrontar a matriz conceitualcultural que possibilita a ramificação desses sistemas. Essa matriz não é arbitrária ou acidental; é a matriz da colonialidade. 


\section{Epistemologia e a opção decolonial}

A reconsideração feita acima significa mais do que um ajuste técnico da teoria. Significa um deslocamento epistemológico básico. Isso é ainda mais necessário quando consideramos a lacuna entre as teorias da colonialidade e da filosofia convencional. Em primeiro lugar, a teoria decolonial questiona a orientação racionalista e positivista que governou o trabalho intelectual convencional do Ocidente durante a Idade Moderna - um questionamento também feito por teóricos pós-coloniais e feministas (por exemplo, HARDING, 1998). Além disso, a teoria decolonial expõe ímpetos mais profundos que estruturam projetos de conhecimento ocidentais e sua imbricação com projetos de conquista - e com a colonialidade do poder de forma mais ampla. Os compromissos epistemológicos formais da filosofia e da ciência estão fundamentados em um conjunto mais obscuro de hábitos, afetos e suposições dominadoras. Investigar a colonialidade é expor e questionar isso.

Contra a imperiosa "objetividade" dos projetos de conhecimento ocidentais, teóricos decoloniais propuseram as noções de "pluriversalidade" (MIGNOLO, 2011) e "ecologia do conhecimento" (SANTOS, 2009), entre outras. Essas propostas destacam a diversidade e a abrangência de conhecimentos e tradições de conhecimento no mundo. Ao fazê-lo, a teoria decolonial recusa o excepcionalismo que reside no trabalho intelectual ocidental - como um pressuposto e ímpeto fundador, se não sempre como um princípio formal. Trata-se aqui de uma questão não só da afirmação da ciência ocidental como a única válida em relação ao método, mas também do seu desejo íntimo por um gesto unicamente autoritário e de seu impulso profundamente arraigado de fugir, em seus argumentos, do contexto e da história. Da perspectiva da "ferida colonial" (MIGNOLO, 2005), os projetos humanistas e iluministas do Ocidente asseguram a maestria do impulso colonizador e o universalismo dominador que assume que "o modo de ser no qual estamos agora (que nos inscrevemos/socializamos para estar) é isomórfico com a própria noção de ser humano" (WYNTER, 2003, p. 330).

Em suma, mesmo que a concepção pluriversal da epistemologia possibilite que a filosofia ocidental exista ao lado de outras tradições, essa mesma possibilidade implicaria repudiar características essenciais suas, e, portanto, reimaginá-la distante da fúria colonizadora que se esconde dentro dos pronunciamentos confiantes, incluindo aqueles que resultam de orientações críticas. Althusser (2009) criticou o pensamento burguês (incluindo o marxismo burguês) por não registrar o deslocamento epistemológico radical promulgado pelo trabalho maduro de Marx. Precisamos aplicar o raciocínio de Althusser 
a si mesmo, a fim de revelar as questões e categorias que uma perspectiva decolonial propõe à ciência da própria teoria (crítica) - questões e categorias que são impensáveis no espaço hermeticamente fechado da autoridade filosófica comum. Evidentemente, a teoria ocidental não pode ser reduzida simplesmente a um conjunto de gestos colonizadores; todavia, separá-la desses gestos, que são constitutivos e onipresentes, implica transformá-la fundamentalmente.

Os problemas epistemológicos destacados nas teorias da colonialidade desafiam a teoria crítica da educação a ir além do tradicional foco no achatamento e na tecnicização do diálogo no currículo e na pedagogia convencionais. Essa última consideração é adaptada a partir das críticas à razão instrumental dos teóricos da Escola de Frankfurt; atualmente, estudiosos as reimplantaram contra as investidas da cultura e da educação escolar neoliberais (por exemplo, GIROUX, 2008). Porém, as questões levantadas pelas investigações epistemológicas na teoria colonial questionam até as formas de currículo crítico e democrático que a educação crítica contrapõe às formas dominantes. Noções descontextualizadas e eurocêntricas de autenticidade e democracia, mesmo que sejam "críticas", também participam de um imaginário colonial. Uma crítica decolonial do currículo desafia os pontos de partida epistemológicos da educação liberal, progressista e crítica e clama por um projeto de reconstrução que se inicia fora dessas tradições, mesmo que seja parcialmente instruído por elas.

\section{Ética, trauma e diálogo}

A organização da modernidade pela colonialidade do poder implica que o problema da ética - e as questões relacionadas, no contexto educacional, da intersubjetividade e do diálogo - é absolutamente político, histórico e material. A análise da colonialidade reorienta fundamentalmente as considerações da ética, uma vez que o contexto colonial recusa esses encontros éticos e seus sujeitos, os quais o campo tradicional da ética visa governar. Conforme descreve Wynter (2006), na modernidade o ser humano foi refeito à imagem do Homem (burguês ocidental) e, como resultado, as comunidades que não correspondem a esse "gênero" humano só podem aparecer aos "olhos internos" do Ocidente como um Outro irremediável - de fato, como uma ausência ou falta de humanidade. Portanto, ao menos na divisão da "ferida colonial", não pode haver intersubjetividade propriamente dita. Isso significa que a ética, nesse contexto, deve se preocupar, em primeiro lugar, com suas próprias condições de possibilidade.

Dentro da condição de colonialidade, o problema ético central é o da possibilidade de reconhecimento do Outro como sujeito, voz e interlocutor. Isso também significa que Revista X, v. 16, n. 1, p. 101-117, 2021. 
o momento ético é necessariamente um momento político e até revolucionário, uma vez que a lógica da colonialidade se fundamenta na impossibilidade desse reconhecimento. $\mathrm{O}$ momento do reconhecimento não é uma reconciliação fácil, mas um calvário do despertar para o ser humano e para a história em si, conforme descreve Enrique Dussel:

De repente, o olhar vítreo do instrumentalizado transforma-se em penetrante. Não é um olhar que objetifica aquele a quem se dirige (como na descrição de Sartre), mas um olhar que personaliza; é o olhar que o torna responsável pela libertação do rosto que se expõe à rejeição e exige justiça. É o olhar exigente que origina misericórdia, justiça, rebelião, revolução, libertação $(1985$, p. 63).

Deve-se notar que o que inaugura a possibilidade de reconhecimento aqui (e de luta revolucionária) é a ação do sujeito "instrumentalizado" (colonizado e dominado) e não a generosidade dos privilegiados e empoderados. Na verdade, para os últimos, reconhecer o olhar (e a subjetividade) do colonizado é, antes de tudo, devastador. Nesse momento, a identificação dos colonizados como inertes, atrasados e abjetos é interrompida. Da mesma forma, a imagem do avanço e da moralidade dos privilegiados é igualmente destruída, assim como a base da identidade e compreensão coloniais.

Em última análise, a ética decolonial deve substituir o pedido de desculpas, devido à dominação que reside no núcleo da ética ocidental, pelos princípios de coexistência, respeito e reciprocidade que são fundamentados na ampla gama de sistemas de valores não-ocidentais existentes ao redor do mundo (ver SMITH, 1999). Nos termos de Wynter (2006), isso significa substituir o sistema do Homem por um novo "Projeto Humano". Mas esse projeto humano também é um projeto revolucionário, uma mudança cataclísmica na ontologia e na epistemologia. Assim como a colonialidade é uma catástrofe contínua para as comunidades negras e pardas em todo o mundo, uma catástrofe normalizada e institucionalizada nos termos da governança global, da mesma forma, o acerto de contas com a transformação do seu legado envolve uma desapropriação revolucionária da elite e da própria branquitude. Nesse processo, povos indígenas e explorados recuperam de uma vez o excedente - material, ontológico, espiritual - que o Ocidente reivindicou para si. Somente com base nessa reintegração de posse um verdadeiro "paradigma planetário" não-dominador e ético (DUSSEL, 1998) pode ser posto em prática.

Essas considerações apontam para a complexidade em tornar real o diálogo crítico e ético na educação. A análise freiriana da oposição entre a educação autoritária (bancária) e dialógica (problematizadora) permanece sendo uma base indispensável para este trabalho. Entretanto, transitar da primeira para a última significa confrontar a 
profundidade da colonialidade, que trabalha para estruturar a intimidade dos espaços da sala de aula tanto quanto para alcançar a sociedade global. Nesse processo, as topografias da branquitude e do poder devem ser fundamentalmente trabalhadas e a distribuição da autoridade discursiva e epistemológica no ensino e na aprendizagem deve ser reorganizada para priorizar aqueles que foram excluídos e marginalizados. A partir dessa perspectiva, o professor nunca pode estabelecer uma posição de liderança epistemológica correta (crítica e democrática), processo que, apesar de sua dificuldade, foi instituído por Freire (1998); ao invés disso, essa autoridade deve ser continuamente questionada e desafiada por compreensões alternativas. Além disso, a Pedagogia Crítica deve atentar para as assimetrias fundamentais entre os estudantes produzidas pela colonialidade. Mais especificamente, a Pedagogia Crítica precisa ficar confortável com a condição de confusão e de nepantla ${ }^{6}$ experenciada por estudantes brancos quando a sua única identificação com o certo, o bom e o capaz é categoricamente recusada e quando as perspectivas dos estudantes de cor são sistematicamente centralizadas. Esses imperativos são parcialmente reconhecidos por educadores críticos e antirracistas, mas em nossa ânsia para criar "comunidades" críticas na sala de aula, com frequência buscamos passar rapidamente pelos antagonismos e impasses dialógicos, que são, a seu modo, produtivos.

Dessa maneira, uma pedagogia ética deve atentar para a economia complexa que organiza as possibilidades de ser e de saber na sala de aula. A ideia da colonialidade oferece uma estrutura essencial e transformadora para pensar nesses níveis o problema do poder na educação. Situando simultaneamente a luta pedagógica na longue durée das relações históricas coloniais e iluminando os registros, de outra forma ocultos, da íntima negociação de poder entre os participantes do ensino e da aprendizagem. A noção de colonialidade e a teoria decolonial, de forma mais ampla, reconstroem e aprofundam de um modo poderoso as possibilidades da Pedagogia Crítica, da teoria educacional crítica e da própria filosofia.

\section{REFERÊNCIAS}

ALTHUSSER, L. The object of capital. In: ALTHUSSER, L.; BALIBAR, E. Reading Capital. Londres: Verso Books, 2009.

\footnotetext{
${ }^{6}$ Nepantla é uma palavra de origem náuatle (asteca) que significa "no meio de" ou "meio". De acordo com Anzaldúa (2002, p. 548-549), nepantla é definido como "The place where different perspectives come into conflict and where you question the basic ideas, tenets, and identities inherited from your family, your education, and your different cultures [O lugar no qual diferentes perspectivas entram em conflito e onde você questiona as ideias, princípios e identidades básicas herdados da sua família, da sua educação e de suas diferentes culturas]" (nota da tradutora).
}

Revista X, v. 16, n. 1, p. 101-117, 2021. 
ANZALDÚA, G. Now let us shift... the path of conocimiento... inner work public acts. In: ANZALDÚA, G.; KEATING, A. This bridge we call home: Radical visions for transformation. Nova Iorque: Routledge, 2002. p. 540-577.

APPLE, M. W. Ideology and curriculum. $3^{\mathrm{a}}$ ed. Nova Iorque: Routledge Falmer, 2004.

CASTRO-GOMEZ, S. (Post)coloniality for dummies: Latin American perspectives on modernity, coloniality and the geopolitics of knowledge. In: MORAÑA, M.; DUSSEL, E.; JÁUREGUI, C. A. (eds.) Coloniality at large: Latin America and the postcolonial debate. Durham: Duke University Press, 2008. p. 259-285.

COLLINS, P. H. Black feminist thought: knowledge, consciousness, and the politics of empowerment. Nova Iorque: Routledge, 2009.

DAVIS, A. Y. Abolition Democracy: beyond empire, prisons, and torture. Nova Iorque: Seven Stories Press, 2005.

DE LISSOVOY, N. Education and violation: conceptualizing power, domination and agency in the hidden curriculum. Race, Ethnicity and Education, [s. l.], v. 15, n. 4, p. 463-484, 2012.

DE LISSOVOY, N. Education and emancipation in the neoliberal era: being, teaching, and power. Nova Iorque: Palgrave Macmillan, 2015.

DE LISSOVOY, N. Injury and accumulation: making sense of the punishing state. Social Justice, [s. l.], v. 42, n. 2, p. 52-69, 2016.

DUSSEL, E. Philosophy of liberation. Tradução de Aquilina Martinez; Christine Morkovsky. Eugene: Wipf \& Stock Publishers, 1985.

DUSSEL, E. Beyond eurocentrism: the world-system and the limits of modernity. In: JAMESON, F.; MIYOSHI, M. (eds.). The cultures of globalization. Durham: Duke University Press, 1998. p. 3-31.

DUSSEL, E. Transmodernity and interculturality: an interpretation from the perspective of philosophy of liberation. TRANSMODERNITY: Journal of peripheral cultural production of the luso-hispanic world, [s. l.], v. 1, n. 3, p. 28-59, 2012.

EVANS-WINTERS, V.; ESPOSITO, J. Other people's daughters: Critical race feminism and black girls' education. Educational Foundations, [s. l.], v. 24, n. 1-2, p. 11-24, 2010.

FANON, F. The wretched of the earth. Tradução de Constance Farrington. Nova Iorque: Grove Press, 1963. 
FANON, F. Black skin, White masks. Tradução de Charles Lam Markmann. Nova Iorque: Grove Press, 1967.

FREGOSO BAILÓN, R. O. The philosophy of liberation of the Bolivarian education system. Tese de doutorado - Universidade do Texas em Austin, [S. l.], 2015a.

FREGOSO BAILÓN, R. O. Sobre una trans-colonialidad para la construcción de la pedagogía crítica descolonial: el caso de la propuesta curricular de la educación Bolivariana. Configuraciones Latinoamericanas, [s. l.], v. 7, n. 13, p. 1-8, 2015 b.

FREIRE, P. Pedagogy of freedom: ethics, democracy, and civic courage. Tradução de Patrick Clarke. Lanham: Rowman \& Littlefield, 1998.

GIROUX, H. A. Against the terror of neoliberalism: politics beyond the age of greed. Boulder: Paradigm Publishers, 2008.

GONZÁLEZ CASANOVA, P. Internal colonialism and national development. Studies in Comparative International Development, [s. l.], v. 1, n. 4, p. 27-37, 1965.

GUAMÁN POMA de AYALA, F. The first new chronicle and good government. Tradução de David Fryed. Indianapolis: Hackett Publishing, 2006.

HARDING, S. Is science multicultural? Postcolonialisms, feminisms, and epistemologies. Bloomington: Indiana University Press, 1998.

LANDER, E. Ciencias Sociales: saberes coloniales y eurocéntricos. In: LANDER, E. (ed.). La colonialidad del saber: eurocentrismo y Ciencias Sociales. Buenos Aires: CLACSO, 2000. p. 11-40.

LARA, G. P. La poda y nuestros retoños: linguistic and literary sprouting against a legacy of pruning. Bilingual Research Journal, [s. l.], v. 40, n. 4, p. 442-443, 2017.

LUGONES, M. Heterosexualism and the colonial/modern gender system. Hypatia, [s. l.], v. 22, n. 1, p. 186-209, 2007.

MALDONADO-TORRES, N. On the coloniality of being. Cultural Studies, [s. l.], v. 21, n. 2, p. 240-270, 2007.

MARX, K. Capital. Tradução de Bem Fowkes. Londres: Penguin Books, 1867/1976. v. 1.

MENDIETA, E. Modernidad, posmodernidad y poscolonialidad: una búsqueda esperanzadora del tiempo. In: CASTRO-GÓMEZ, S. (ed.). Teorías sin disciplina: 
latinoamericanismo, poscolonialidad y globalización en debate. México: Miguel Ángel Porrúa, 1998. p. 147-166.

MIGNOLO, W. Local histories/global designs: coloniality, subaltern knowledges, and border thinking. Princeton: Princeton University Press, 2000.

MIGNOLO, W. The idea of Latin America. Malden: Blackwell Publishing, 2005.

MIGNOLO, W. The geopolitics of knowledge and the colonial difference. In: MORAÑA, M.; DUSSEL, E.; JÁUREGUI, C. A. Coloniality at large: Latin America and the postcolonial debate. Durham: Duke University Press, 2008. p. 235-258.

MIGNOLO, W. The darker side of western modernity. Durham: Duke University Press, 2011.

PRECIADO, J. C. América Latina no sistema-mundo: questionamentos e alianças centroperiferia. Nuevos Escenarios para la Integración en América Latina. Cadernos $C R H$, [s. l.], 2008. Disponível em: http://dx.doi.org/10.1590/S0103-49792008000200005.

QUIJANO, A. Colonialidad y modernidad/racionalidad. Perú Indígena, [s. l.], v. 13, n. 29, p. 11-20, 1992.

QUIJANO, A. Colonialidad del Poder, Eurocentrismo y América Latina. In: LANDER, E. (ed.). Colonialidad del saber y eurocentrismo. Buenos Aires: UNESCO-CLACSO, 2000. p. 201-246.

QUIJANO, A. Coloniality at Large: Latin America and the postcolonial debate. In: MORAÑA, M.; DUSSEL, E.; JÁUREGUI, C. A. (eds.). Coloniality at Large: Latin America and the postcolonial debate. Durham: Duke University Press, 2008. p. 181-224.

ROMO TORRES, R. Pedagogía, epistemología y poesía: una triada para pensar e imaginar desde los sujetos. México: Centro Universitario de Ciencias Sociales y Humanidades, Universidad de Guadalajara, 2016.

ROSAS, M. M.; CALDERÓN, R. G. La Apropiación de la Ciencia como Política Pública en México. In: TORRES, F. L. (ed.). Estudios Políticos y Sociales: Retos de la Sociedad Contemporánea. México: Universidad de Guadalajara, 2015.

SANTOS, B. de. S. A non-occidentalist west? Learned ignorance and ecology of knowledge. Theory, Culture \& Society, [s. l.], v. 26, n. 7-8, p. 103-125, 2009.

SMITH, L. T. Decolonizing methodologies: research and indigenous peoples. Londres e Dunedin: Zed Books/University of Otago Press, 1999. 
WALSH, C. Entretejiendo lo Pedagógico y lo Decolonial: Luchas, caminos y Siembras de Reflexión-Acción para Resistir, Re (existir) y Re (vivir). Colômbia: Alternativas, 2017.

WYNTER, S. Unsettling the coloniality of being/power/truth/freedom: towards the human, after man, its overrepresentation - an argument. The New Centennial Review, [s. l.], v. 3, n. 3, p. 257-337, 2003.

WYNTER, S. On how we mistook the map for the territory, and re-imprisoned ourselves in our unbearable wrongness of being, of Désètre: black studies toward the human project. In: GORDON, L. R.; GORDON, J. A. Not only the master's tools: AfricanAmerican studies in theory and practice. Boulder: Paradigm Publishers, 2006. p. 107-169. 